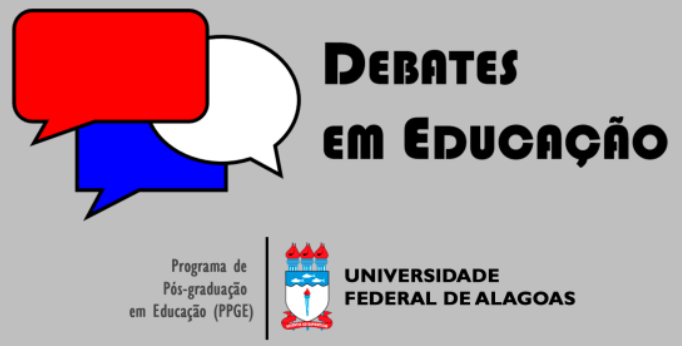

ISSN Eletrônico 2175-6600

Vol. I | | No. 23 | Jan./Abr. | 2019

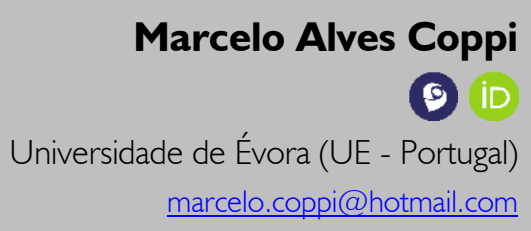

Clarilza Prado de Sousa

9 iD

Pontifícia Universidade Católica de São Paulo (PUC-SP) clarilza.prado@gmail.com

\section{ESTUDO DA ALFABETIZAÇÃO CIENTÍFICA DE ALUNOS DO 9० ANO DO ENSINO FUNDAMENTAL DE UM COLÉGIO PARTICULAR DA CIDADE DE SÃO PAULO}

\section{RESUMO}

$\bigcirc$ ensino de Ciências tem como principal objetivo o desenvolvimento da Alfabetização Científica, a qual é entendida como a aquisição de um conjunto de saberes científicos e tecnológicos que capacita o aluno a operar e se posicionar no mundo em que vive, atuando como um cidadão. $\bigcirc$ objetivo deste artigo foi mensurar a quantidade de alunos cientificamente alfabetizados do $9^{\circ}$ ano de um Colégio, por meio do Teste de Alfabetização Cientíica Básica (TACB) e comparar os Planos de Ensino de Ciências do Colégio com a matriz curricular do programa Science for All Americans. Os resultados evidenciaram que 15,3\% dos alunos são cientificamente alfabetizados e que a maior parte dos conceitos do programa Science for All Americans não são abordados nos Planos de Ensino de Ciências do Colégio.

Palavras-chave: Alfabetização Científica. Ensino de Ciências. Teste de Alfabetização Científica Básica.

\section{STUDY OF THE SCIENTIFIC LITERACY OF STUDENTS OF THE 9TH GRADE OF ELEMENTARY SCHOOL OF A PRIVATE SCHOOL IN SÃO PAULO CITY}

\footnotetext{
ABSTRACT

Science education has as its main objective the development of Scientific Literacy which is understood as the acquisition of a set of scientific and technological knowledge that enables the student to operate and position himself in the world that he lives, acting as a citizen. The aim of the article was to measure the quantity of scientifically literate students from the 9th grade of the School using the Test of Basic Scientific Literacy (TBSL), and to compare the Science Teaching Plans of the School with the curriculum matrix of the program Science for All Americans. The results showed that $15.3 \%$ of the students are scientifically literate and that most of the concepts in the Science for All Americans program are not covered in the College Science Teaching Plans.
}

Keywords: Scientific Literacy. Science teaching. Basic Scientific Literacy Test.

Submetido em: $18 / 11 / 2018$

Aceito em: 18/02/2019

Ahead of print em: 08/04/2019

Publicado em: 25/04/2019

dc http://dx.doi.org/10.28998/2175-6600.2019v| In23p | 69-185 


\section{INTRODUÇÃO}

A Alfabetização Científica pode ser definida como a aquisição de um conjunto de saberes científicos e tecnológicos que capacitaria um indivíduo a entender, interpretar, operar e atuar no mundo em que vive, podendo exercer seu papel de cidadão, livre de preconceitos, falsas visões e representações que estão impregnadas no conhecimento de senso comum. Para alcançar esses propósitos, cabe ao ensino de Ciências romper com o ensino baseado somente na transmissão de conteúdos e propor um ensino que possibilite aos alunos um desenvolvimento cultural e científico que os tornem cidadãos críticos e aptos para encontrar respostas para os problemas da sociedade em que vivem (MARTELLI, 2004).

O ensino de Ciências na Educação Básica visa ao desenvolvimento da Alfabetização Científica, na qual o aluno, dentre outras coisas, aprende a contrapor o conhecimento ingênuo a um conhecimento fundamentado na experimentação controlada, na elaboração e no teste de hipóteses e no estabelecimento de relações entre fatos, fenômenos ou ideias já comprovadas cientificamente por teorias e metodologias rigorosas.

Essa ideia é amplamente aceita pelos especialistas da área. Santos (2007) afirma ser necessária a discussão dos diferentes significados que vêm sendo atribuídos à educação científica com o propósito de integrar as áreas do currículo, filosofia e políticas educacionais que objetivam analisar o papel da educação científica na formação do cidadão.

Nesse sentido, o ensino de Ciências deve passar por transformações. É necessário deixar de lado a mera transmissão de conteúdos para estimular o espírito científico dos alunos, levando em consideração as mudanças históricas, culturais, políticas e tecnológicas que a sociedade vem passando (SANTOS, 2006).

Até a década de 1960, a qualidade do Ensino de Ciências era julgada pela quantidade de conteúdos transmitidos pelo professor. No início da década de 1970, o movimento pedagógico conhecido como "Ciência, Tecnologia e Sociedade" (CTS) passou a considerar a relação entre as Ciências com a Tecnologia e dessas com a sociedade. Nas décadas seguintes, as práticas no ensino de Ciências passaram a ter como foco o aluno, visando à formação de cidadãos (SANTOS, 2006).

A tendência CTS foi vastamente praticada durante a década de 1990, época em que, segundo Nascimento, Fernandes e Mendonça (2010, p. 232), "o ensino de Ciências passou a contestar as metodologias ativas e a incorporar o discurso da formação do cidadão crítico, consciente e participativo".

No final da década de 1990, com a aprovação da nova Lei de Diretrizes e Bases da Educação nº 9.394/96, e durante a década de 2000, a educação científica teve como foco a formação do cidadão, visando às complexas interações entre a Ciência, a Tecnologia e a Sociedade. Nascimento, Fernandes e Mendonça (20।0) afirmam que a formação do cidadão deve ser o foco do ensino de Ciências, fazendo com que os alunos passem a reconsiderar suas visões a respeito da realidade do mundo, questionar suas 
confianças nas instituições, avaliar seu modo de vida e analisar a consequência das suas ações no âmbito da coletividade.

Durante esse percurso, as transformações no ensino de Ciências foram orientadas por diferentes tendências que, até hoje, influenciam as práticas de sala de aula (BRASIL, 1997). Krasilchik (2000, p. 85) afirma que as reformas educacionais estão relacionadas com o reconhecimento da Ciência e da Tecnologia no desenvolvimento da nação. Segundo a autora,

(...) na medida em que a Ciência e a Tecnologia foram reconhecidas como essenciais no desenvolvimento econômico, cultural e social, o ensino das Ciências em todos os níveis foi também crescendo de importância, sendo objeto de inúmeros movimentos de transformação do ensino, podendo servir de ilustração para tentativas e efeitos das reformas educacionais.

Atualmente, as propostas para o ensino de Ciências estão voltadas para o desenvolvimento da Alfabetização Científica da população, ou seja, o conhecimento de conceitos ligados à Ciência e à Tecnologia, necessários para compreender os benefícios e os impactos dessas áreas na sociedade (MILLER, 1996). Pesquisadores de Ciências na área da Educação vêm-se esforçando no sentido de esclarecer que o ensino de Ciências deve ser modificado e orientado para a pratica da cidadania, focando na formação de cidadãos capazes de conhecer e intervir na sociedade em que vivem (SANTOS, 2006).

Entretanto, ainda existe certa resistência na implantação dessa tendência no ensino de Ciências. De acordo com os antigos Parâmetros Curriculares Nacionais (PCN) de Ciências Naturais, substituídos, em 20 17, pela Base Nacional Comum Curricular (BNCC), embora o objetivo da Alfabetização Científica estivesse claro, "sua presença efetiva nas salas de aula da educação fundamental está muito longe do ideal, nas quais ainda persistem as velhas práticas de transmissão de conteúdos" (BRASIL, 1997, p. 21).

O ensino de Ciências deve, portanto, promover a democratização do conhecimento da sociedade favorecendo uma aprendizagem que desenvolva discussões acerca das dimensões sociais, políticas e econômicas que permeiam as relações entre Ciência, Tecnologia e Sociedade, tendo como objetivo a formação de cidadãos críticos, aptos para ler a natureza em que vivem, e capazes de tomar decisões a respeito das mudanças que ocorrem a sua volta. (SANTOS, 2006). A Academia Brasileira de Ciências (2007, p. VII) corrobora com essa perspectiva do ensino de Ciências alegando que "o ensino de Ciências estimula o raciocínio lógico e a curiosidade, ajuda a formar cidadãos mais aptos a enfrentar os desafios da sociedade contemporânea e fortalece a democracia", além disso, garante à população melhores condições, para participar dos debates científicos do seu cotidiano.

Para tanto, a educação científica deve possibilitar aos alunos o desenvolvimento de habilidades e competências que lhes permitam observar fenômenos, formular hipóteses, experimentar e verificar as conclusões. Trata-se de um processo que, apesar de lento, estabelece uma base sólida para que o aluno 
compreenda o que acontece ao seu redor e consiga interferir no meio em que vive. (ACADEMIA BRASILEIRA DE CIÊNCIAS, 2007).

Esse conjunto de conhecimentos básicos da Ciência e da Tecnologia, deve ser capaz de capacitar os indivíduos a intervirem em sua realidade e se comportarem como cidadãos responsáveis, aptos a se posicionarem acerca das questões políticas e científicas, voltadas para uma Ciência democrática, que permita, como definem Nascimento-Schulze, Camargo e Wachelke (2006), uma Alfabetização Científica.

Esse termo surgiu na década de 1950 e, como expõe Laugksch (2000, p. 72), "muito provavelmente apareceu impresso pela primeira vez quando Paul Hurd (Hurd, 1958) usou em uma publicação intitulada Science Literacy: seu significado para escolas americanas". Desde então, uma das questões que norteiam a grande discussão sobre a Alfabetização Científica é a definição (LAUGKSCH, 2000).

Para Nascimento-Schulze (2006, p. 100), o termo "Alfabetização Científica" (Scientific Literacy) é mais utilizado nos Estados Unidos, sendo conhecido na Inglaterra como "compreensão do público sobre a Ciência" (public understanding of science) e na França como "la culture scientifique". No Brasil, devido a uma diferença de tradução do termo literacy, empregam-se os termos Alfabetização Científica e Letramento Científico. O presente artigo utiliza o termo Alfabetização Científica.

Evidentemente, essa diferenciação de termos não se mostra muito relevante, uma vez que todos os significados estão sempre relacionados a uma compreensão de conhecimentos sobre a natureza, Ciência e Tecnologia (OLIVEIRA; SILVA-FORSBERG, 201 I).

Importante, no entanto, é considerar os parâmetros que definem o sujeito cientificamente alfabetizado. Para Miller (1996) para ser assim considerado, o sujeito deve conhecer os conceitos científicos, compreender o método utilizado pela Ciência, assim como, entender o impacto da Ciência e da Tecnologia sobre a sociedade. Segundo o referido autor (1996, p. 187), "a Alfabetização Científica deve ser vista como o nível de compreensão da ciência e tecnologia necessária para atuar minimamente como cidadãos e consumidores em nossa sociedade".

Em estudos anteriores, (MILLER, 1893a, 1987, 1989, 1992 in MILLER, 1996), Miller defende que para alcançar a Alfabetização Científica é necessário um vocabulário científico básico de termos e conceitos, o entendimento dos métodos científicos e a compreensão do impacto da Ciência e da Tecnologia na sociedade.

Para Caniçali (20।4) a Ciência é uma linguagem e, dessa forma, alcançar a Alfabetização Científica é ser capaz de ler e interpretar os fenômenos naturais, comparando a dificuldade desse processo com a dificuldade de ler um texto em um idioma desconhecido. Chassot (2000, p. 19) compartilhando a ideia, afirma que a Alfabetização Científica deve ser entendida como "o conjunto de conhecimentos que facilitariam aos homens e mulheres fazer uma leitura do mundo onde vivem". 
Tal perspectiva encontra abrigo, também, nas ideias de Viecheneski, Lorenzetti e Carletto (20 I2, p. 858) ao defenderem que os conhecimentos adquiridos pelo indivíduo por meio do domínio da linguagem das Ciências "são fundamentais para sua ação na sociedade, auxiliando-o nas tomadas de decisões que envolvam o conhecimento científico".

Corroborando com essa ideia de conhecimento da Ciência, a Organização para a Cooperação e Desenvolvimento Econômico (OCDE) afirma que "o conhecimento da Ciência e da Tecnologia de base científica contribui de forma significativa para a vida pessoal, social e profissional dos indivíduos, sua compreensão é fundamental para a preparação para a vida de uma pessoa jovem" (INEP, 20 I 5, p. 3).

Nesse sentido, autores como o Lorenzetti e Delizoicov (200 I), Viecheneski, Lorenzetti e Carletto (2012), Chassot (2003) e Viecheneski e Carletto (2013) propõem que a Alfabetização Científica deva ser trabalhada desde os anos iniciais do Ensino Fundamental. Para Lorenzetti e Delizoicov (200 I, p. 43),

(...) a Alfabetização Científica no ensino de Ciências Naturais nas séries iniciais é aqui compreendida como o processo pelo qual a linguagem das Ciências Naturais adquire significados, constituindo-se um meio para o indivíduo ampliar seu universo de conhecimento, a sua cultura, como cidadão inserido na sociedade.

Chassot (2003) vai além, afirmando que a Alfabetização Científica deve ser uma preocupação significativa não só para o Ensino Fundamental e Ensino Médio, mas, também, para o Ensino Superior. Segundo o autor (2003, p. 23), "sonhadoramente, ampliaria a proposta para incluir também, mesmo que isso possa causar arrepio em alguns, o ensino superior".

No Brasil, a ideia de Alfabetização Científica, proposta desde a década de 1960, está presente, também, na BNCC, utilizando o termo Letramento Científico. Trata-se de um documento que define o conjunto de aprendizagens essenciais que todos os alunos devem desenvolver ao longo da Educação Básica e, na área das Ciências da Natureza, estabelece "um compromisso com o desenvolvimento do letramento científico, que envolve a capacidade de compreender e interpretar o mundo (natural, social e tecnológico), mas também de transformá-lo com base nos aportes teóricos e processuais das ciências" (BRASIL, 2017, p. 319).

De acordo com a BNCC, a finalidade do letramento científico não envolve apenas aprender Ciências, mas, também, o desenvolvimento do exercício da cidadania, cabendo ao Ensino Fundamental assegurar o "acesso à diversidade de conhecimentos científicos produzidos ao longo da história, bem como a aproximação gradativa aos principais processos, práticas e procedimentos da investigação científica" (BRASIL, 2017, p. 319), possibilitando que esses alunos "tenham um novo olhar sobre o mundo que os cerca, como também façam escolhas e intervenções conscientes e pautadas nos princípios da sustentabilidade e do bem comum" (BRASIL, 2017, p. 319) 
No âmbito internacional, a OCDE desenvolve e coordena, desde 2000, o Programme for International Student Assessment (PISA), o qual avalia a preparação dos estudantes na faixa dos I 5 anos (idade que se pressupõe o término da escolaridade básica obrigatória na maioria dos países), nas áreas de Leitura, Matemática e Ciências (INEP, 20 I5).

Os resultados dessa avaliação têm possibilitado produzir indicadores que contribuem para a discussão da qualidade da educação nos países participantes. No caso de Ciências, o objetivo é avaliar o Letramento Científico ${ }^{1}$, que foi definido em 2003 como "a capacidade de usar o conhecimento científico para identificar questões e tirar conclusões baseadas em evidências, a fim de compreender e ajudar a tomar decisões sobre o mundo natural e as mudanças feitas a ele por meio da atividade humana" (INEP, 20 I 5, p. 10).

Outro instrumento utilizado para mensurar a Alfabetização Científica dos alunos é o Teste de Alfabetização Científica Básica (TACB). Desenvolvido e validado pelos pesquisadores sul-africanos Laugksch e Spargo (1996), o teste se baseia em recomendações e em uma escala de avaliação propostas pelo Science for All Americans, programa que estabelece recomendações sobre os conhecimentos e habilidades que todos os estudantes americanos deveriam ter nestas disciplinas ao concluírem o Ensino Médio (CAMARGO et al., 20I I).

O TACB conta com I 10 itens que abordam cinco das doze seções que compõem o programa Science for All Americans, sendo elas: a natureza da Ciência; a natureza da Tecnologia; o ambiente físico; o ambiente vivo e o organismo humano (AAAS, 1989). Os I I 0 itens do teste estão divididos em três sub testes distintos: natureza da Ciência (contendo itens referentes à seção na natureza da Ciência); conhecimento do conteúdo da Ciência (contendo itens relacionados às seções do ambiente físico; ambiente vivo e organismo humano) e impacto da Ciência e da Tecnologia na sociedade (contendo itens referentes à seção da natureza da Tecnologia). Esses foram baseados nas três dimensões constitutivas de Alfabetização Científica propostas por Miller (1983), natureza da Ciência, conhecimento cognitivo da Ciência e impacto da Ciência e Tecnologia na sociedade.

De acordo com Miller ( 1983), a dimensão da natureza da Ciência faz referência à compreensão dos processos de uma pesquisa científica, inclusive sua definição e os meios utilizados. Em relação à segunda dimensão (conhecimento dos conteúdos da Ciência) o autor aponta que para ser considerado cientificamente alfabetizado é necessário um vocabulário científico mínimo que permita ao indivíduo participar da discussão pública de questões relacionadas à Ciência e à Tecnologia. Já a terceira dimensão (impacto da Ciência e Tecnologia na sociedade), o autor aborda as questões referentes à presença, cada vez maior, dessas duas áreas nas discussões de políticas públicas, assim como no dia a dia da sociedade.

I O PISA utiliza o termo Letramento Científico ao invés de Alfabetização Científica. 
O TACB é apresentado de forma dicotômica, sendo possível a atribuição de um ponto para cada questão correta e zero para as questões erradas, tornando-se possível contabilizar a quantidade de acertos e erros no geral e por sub teste (NASCIMENTO-SCHULZE, 2006). De acordo com Miller (1983, p. 42) "uma simples mensuração da Alfabetização Científica requer uma pontuação mínima aceitável em todas as três áreas para que um indivíduo possa ser considerado cientificamente alfabetizado". Tal pontuação foi proposta por Laugksch e Spargo ( 1996), declarando que para ser considerado cientificamente alfabetizado é necessário que o aluno obtenha o mínimo de 13 acertos no sub teste da natureza da Ciência, 45 no sub teste do conhecimento dos conteúdos da Ciência e 10 no sub teste do impacto da Ciência e Tecnologia na sociedade.

Analisando pesquisas correlatas desenvolvidas que utilizaram o TACB em sua metodologia, ficou evidente que escassos estudos utilizaram o teste proposto por Laugksch e Spargo (1996) ou então uma versão reduzida desse para avaliar a Alfabetização Científica de alunos que cursavam os anos finais do Ensino Fundamental e Médio e Superior.

Há que registrar, no entanto, que o estudo realizado pelos próprios autores do teste, Laugksch e Spargo (1999), analisou os índices de Alfabetização Científica de 4.223 estudantes recém-formados no Ensino Básico que ingressaram na Universidade ou em um Ensino Técnico. Seus resultados demonstraram que apenas 36\% dos alunos participantes da pesquisa obtiveram sucesso no teste, a ponto de serem considerados cientificamente alfabetizados (LAUGKSCH; SPARGO, 1999).

Também deve ser observado o estudo de Nascimento-Schulze (2006) que aplicou uma versão traduzida do TACB para parte dos alunos do Ensino Médio de diferentes escolas públicas e particulares do Estado de Santa Catarina. Os resultados revelaram que apenas 36,5\% dos alunos foram considerados cientificamente alfabetizados.

Oliveira e Silva-Forsberg (201 I) aplicaram uma versão reduzida do TACB, contendo apenas 60 questões, a 200 estudantes da última série do Ensino Fundamental II das escolas municipais de Manaus Amazonas. Além de conter menor quantidade de questões o teste aplicado abordou somente dois sub testes, contendo 40 itens relacionados ao sub teste dos conteúdos de Ciências naturais e outros 20 sobre o sub teste dos impactos da Ciência e Tecnologia na Sociedade. Os resultados evidenciaram que 66,5\% dos alunos obtiveram o mínimo de acertos para serem considerados cientificamente alfabetizados, que no estudo representavam 60\% ou mais de acerto nas 60 questões. Embora os resultados tenham sido positivos, os autores consideram que os conhecimentos dos alunos sobre Ciências são limitados (OLIVEIRA; SILVA-FORSBERG, 20I I).

O único trabalho encontrado que apresentou resultados positivos ao aplicar o TACB na íntegra foi realizado por Camargo et al. $(20 \mathrm{I}$ I). Nesse estudo, o teste foi aplicado a 45 alunos ingressantes e I3 alunos concluintes do curso de Licenciatura em Química de uma Universidade Comunitária do Estado do 
Rio Grande do Sul. Os resultados revelaram que todos os estudantes analisados apresentaram um índice de Alfabetização Científica acima do nível proposto por Laugksch e Spargo (1996), sendo considerados cientificamente alfabetizados (CAMARGO et al. 20 I I).

Os estudos anteriores permitiram equacionar o presente estudo, que se define com o objetivo de analisar a Alfabetização Científica dos alunos do $9^{\circ}$ ano do Ensino Fundamental do Colégio, por meio do Teste de Alfabetização Científica Básica - TACB desenvolvido por Laugksch e Spargo ( 1996).

Entendendo que o desenvolvimento do ensino nas escolas é regido pelo Plano de Ensino, procurou-se também analisar os Planos de ensino de Ciências com base na matriz proposta pelo programa Science for All Americans. Os resultados dessas análises permitiram a proposição de subsídios para a formação em serviço de professores de Ciências, na Educação Básica, possibilitando a eles compreender as habilidades básicas que poderiam ser desenvolvidas e, também, aquelas que os alunos apresentam maiores dificuldades.

\section{A PESQUISA}

O estudo foi realizado em uma Escola particular da capital de São Paulo - Brasil que, a partir de agora, será denominada de Colégio.

Segundo o INEP (20 I 4), o Colégio atende a um público com nível socioeconômico muito alto e conta com uma infraestrutura que dispõe de três Laboratórios de Ciências (Biologia, Física e Química), Laboratórios de Informática, Biblioteca, quadra de esportes, campo de futebol, entre outros. Cada sala de aula possui, além da lousa, um computador com internet e um projetor inteligente disponível para o uso do professor (QEDU, 20--a).

Em relação ao corpo docente, este se apresenta especializado na sua área de formação. De acordo com o INEP (20।4), a média de professores com formação no Ensino Superior é de 83,3\% na Educação Infantil, 96,2\% no Ensino Fundamental e 96,7\% no Ensino Médio (INEP, 2014).

O Colégio apresenta uma alta taxa de aprovações em todos os ciclos do Ensino Básico. Segundo o QEDU (20--b), a taxa de aprovação do Ensino Fundamental nos anos iniciais é de 97,7\% e nos anos finais de 93, I \%. No Ensino Médio a taxa é de 95,9\%.

Além de altos índices de aprovações, o Colégio apresentou, também em 20l4, baixas taxas de reprovações: nos anos iniciais do Ensino Fundamental a taxa de reprovação foi de 0,3\%; nos anos finais do Ensino Fundamental esta taxa foi de 6,9\%; e no Ensino Médio a taxa foi de 4, I\% (QEDU, 20--b).

A fim de analisar a formação acadêmica dos alunos do $9^{\circ}$ ano do Ensino Fundamental em relação à Alfabetização Científica e de propor uma formação para os professores de Ciências, o estudo foi realizado em duas fases: fase I - comparação das seções do programa Science for All Americans, utilizados no TACB, 
com os Planos de Ensino de Ciências do Ensino Fundamental Il do Colégio; fase 2 - aplicação do Teste de Alfabetização Científica Básica.

\section{I Fase I - Comparação das seções do programa Science for All Americans, utilizados no TACB, com os Planos de Ensino de Ciências do Ensino Fundamental II do Colégio.}

A análise da matriz do programa Science for All Americans e dos Planos de Ensino de Ciências de todos os anos do Ensino Fundamental II foi feita a partir de um roteiro de comparação composto por cinco elementos: três deles relacionados ao programa Science for All Americans, indicando o conteúdo, a seção e a subseção do programa, correspondentes a cada item do TACB, e outros dois relacionados ao Plano de Ensino de Ciências do Colégio, informando se determinado conteúdo consta no documento e o ano em que ele é trabalhado.

O roteiro de comparação permitiu indicar a presença e a ausência dos conceitos referentes à Alfabetização Científica, propostos pela matriz do programa Science for All Americans, no Plano de ensino de Ciências do Ensino Fundamental II do Colégio.

Esses conceitos estão agrupados em cinco seções no programa Science for All Americans: a natureza da Ciência; a natureza da Tecnologia; o ambiente físico; o ambiente vivo e o organismo humano. Dessa forma, as sínteses foram realizadas de acordo com cada sessão.

\section{I.I A natureza da Ciência}

A sessão da natureza da Ciência aborda conceitos relacionados aos fundamentos básicos da Ciência, como por exemplo, a observação, o pensamento, a experimentação e a validação dos fenômenos (AAAS, 1989). Essa seção contém vinte e dois itens e está dividida em três subseções: a visão científica do mundo; métodos científicos de investigação e a natureza do empreendimento científico (AAAS, 1989).

A comparação destes itens com o do Plano de Ensino de Ciências do Ensino Fundamental II do Colégio indicou que apenas nove dos vinte e dois itens $(40,9 \%)$ referentes a essa seção estão contemplados no Plano de Ensino, sendo todos eles pertencentes ao conteúdo do $9^{\circ}$ ano.

Ressalta-se que todos os itens da subseção da natureza da Ciência estão presentes apenas no Plano de Ensino do $9^{\circ}$ ano. Deixa, portanto, de proporcionar aos outros anos deste ciclo o contato com a investigação científica e com atividades que buscam "definir problemas, levantar, analisar e representar resultados; comunicar conclusões e propor intervenções" (BRASIL, 2017, p. 322). 
A pesquisa de Carvalho (200I, p. 146) reforça os dados encontrados quando afirma que em nenhum nível do ensino de Ciências "a dimensão epistemológica tem estado presente de forma articulada e explicitamente consciente por parte da maioria dos professores em sala de aula".

\section{I.2 A natureza da Tecnologia}

A seção da natureza da Tecnologia aborda conhecimentos relativos à importância da produção e da utilização da Tecnologia para o desenvolvimento da sociedade, assim como a importância da sua aliança com a Ciência. Contém dezesseis itens divididos em três subseções: a Ciência e a Tecnologia; princípios da Tecnologia e os projetos e sistemas que conectam a Tecnologia com a sociedade (AAAS, 1989).

Ao comparar os itens dessa seção com o Plano de Ensino de Ciências do Ensino Fundamental II do Colégio, verificou-se que, dos dezesseis itens, apenas um $(6,25 \%)$ estava contemplado nos Planos de Ensino.

A ausência dos conceitos referentes à seção da natureza da Tecnologia nos Planos de ensino de Ciências do Colégio evidencia as ideias de Teixeira (2003, p. 178), quando o autor admite que o ensino das disciplinas científicas "fica demarcado pelas abordagens internalistas que privilegiam profundamente os conteúdos específicos de cada disciplina, desconsiderando os acontecimentos presentes na sociedade", como por exemplo, o avanço da tecnologia e sua capacidade de modificar a sociedade.

Tal defasagem desconsidera as competências apontadas pela BNCC de Ciências da Natureza, as quais englobam a capacidade de:

(...) analisar, compreender e explicar características, fenômenos e processos relativos ao mundo natural, social e tecnológico (incluindo o digital), como também as relações que se estabelecem entre eles, exercitando a curiosidade para fazer perguntas, buscar respostas e criar soluções (inclusive tecnológicas) com base nos conhecimentos das Ciências da Natureza. (BRASIL, 2017 p. 322).

\section{I.3 O ambiente físico}

A seção do ambiente físico é a que contém a maior quantidade de itens no Teste de Alfabetização Científica Básica, vinte e nove no total. Essa seção apresenta conceitos relacionados ao conhecimento básico da estrutura geral do Universo e dos princípios físicos que o regem, oferecendo relativo destaque ao Planeta Terra e ao seu Sistema Solar. Ela é dividida em sete subseções: o Universo, o planeta Terra, processos de formação do planeta Terra, a estrutura da matéria, as transformações de energia, o movimento e as forças da natureza (AAAS, 1989). 
Na comparação dos itens dessa seção com os Planos de ensino de Ciências do Ensino Fundamental II do Colégio, constatou-se que vinte e sete dos vinte e nove itens $(93,1 \%)$ desta seção estão contemplados nos Planos de Ensino.

Levando em consideração que a maior parte dos itens dessa seção é contemplada nos Planos de ensino de Ciências do Colégio e que seus conteúdos estão distribuídos em todos os anos desse ciclo do Ensino Fundamental II, pode-se inferir que os conceitos relativos ao ambiente físico, propostos pelo programa Science for All Americans e que fazem parte dos conceitos necessários para a Alfabetização Científica, estão sendo trabalhados em sala de aula. Além disso, estão de acordo com o previsto na BNCC, ao apontar que a unidade temática "matéria e energia", assim como as outras temáticas, se repetem ao longo do Ensino Fundamental e "contemplam o estudo de materiais e suas transformações, fontes e tipos de energia utilizados na vida em geral, na perspectiva de construir conhecimento sobre a natureza da matéria e os diferentes usos da energia" (BRASIL, 2017, p. 323).

\section{I.4 O ambiente vivo}

Esta seção do Science for All Americans descreve conceitos básicos sobre as diferentes formas de vida existentes, suas necessidades básicas para sobrevivência, sua interação com os organismos da sua espécie e de espécies diferentes e a importância da preservação ambiental na manutenção dos ecossistemas. Compõe vinte e quatro itens do Teste de Alfabetização Científica Básica, divididos em seis subseções: a diversidade da vida, a hereditariedade, as células, a independência da vida, o fluxo de matéria e energia e a evolução da vida (AAAS, 1989).

A análise revela que dezesseis dos vinte e quatro itens (66,6\%) estão contemplados nos Planos de Ensino de todos os anos do Ensino Fundamental II. Percebe-se que a maior parte dos conceitos está presente em todos os anos do Ensino Fundamental II. Entretanto, verifica-se a ausência dos conteúdos relacionados à informação genética, ecologia e evolução da vida. Essa carência nos Planos de Ensino de Ciências do Colégio é considerada significante quando relacionada aos objetivos da Alfabetização Científica, já que praticamente um terço dos conteúdos não está sendo trabalhado.

É válido ressaltar que, além de fazer parte do programa Science for All Americans, esses conceitos constam, também, na BNCC de Ciências da Natureza, a qual estabelece que, ao estudar Ciência,

(...) as pessoas aprendem a respeito de si mesmas, da diversidade e dos processos de evolução e manutenção da vida, do mundo material - com os seus recursos naturais, suas transformações e fontes de energia -, do nosso planeta no Sistema Solar e no Universo e da aplicação dos conhecimentos científicos nas várias esferas da vida humana. Essas aprendizagens, entre outras, possibilitam que os alunos compreendam, expliquem e intervenham no mundo em que vivem (BRASIL, 2017 p. 323). 


\section{I.5 O organismo humano}

A última seção do programa Science for All Americans presente no Teste de Alfabetização Científica Básica é a do organismo humano, contando com dezenove itens. Esses abordam conceitos relacionados às características da espécie humana como, por exemplo, a composição e a fisiologia corporal, a relação com seus ancestrais e os conceitos relacionados à sua saúde. Ela é composta por seis subseções: a identidade humana, o desenvolvimento humano, as funções básicas, a aprendizagem, a saúde física e a saúde mental (AAAS, 1989).

A análise constatou que dez dos dezenove itens (52,6\%) estão contemplados nos Planos de Ensino de Ciências dos $8^{\circ}$ e $9^{\circ}$ anos do Colégio. Percebe-se que apenas cerca da metade dos itens dessa seção estão sendo trabalhados nas aulas de Ciências do Colégio. Os conceitos deixados de lado referem-se ao desenvolvimento humano, à saúde mental e ao aprendizado, criando uma grande lacuna para o desenvolvimento da Alfabetização Científica dos alunos, já que esses deixam de compreender o valor dos cuidados que envolvem o desenvolvimento fetal e embriológico, e a importância das saúdes física e mental e dos serviços de saúde e educação para o crescimento e desenvolvimento do ser humano.

Além disso, há de se observar que consta na BNCC de Ciências da Natureza que, ao final do Ensino Fundamental, os alunos devem apresentar "condições de ser protagonistas na escolha de posicionamentos que valorizem as experiências pessoais e coletivas, e representem o autocuidado com seu corpo e o respeito com o do outro, na perspectiva do cuidado integral à saúde física, mental, sexual e reprodutiva" (BRASIL, 2017 p. 34I).

\subsection{Fase 2 - Aplicação do TACB}

Para mensurar a quantidade de alunos cientificamente alfabetizados, foi utilizada a versão traduzida do TACB desenvolvido por Laugksch e Spargo (1996). O teste foi aplicado a uma população de I 89 alunos do $9^{\circ}$ ano do Ensino Fundamental do Colégio, os quais responderam o teste em sala de aula, com duração de 50 minutos, na presença do pesquisador responsável.

Após a coleta dos dados, foi calculada a proporção de alunos que havia acertado a quantidade mínima de itens nos três sub testes: 13 no sub teste da natureza da Ciência, 45 no sub teste do conhecimento dos conteúdos da Ciência e 10 no sub teste do impacto da Ciência e Tecnologia na Sociedade.

Os resultados da aplicação do Teste de Alfabetização Científica Básica aos alunos do $9^{\circ}$ ano do Ensino Fundamental do Colégio indicou que apenas 29 de 189 alunos, ou seja, 15,3\% podem ser considerados cientificamente alfabetizados. 
Os dados referentes aos índices de alunos cientificamente alfabetizados são apresentados na Tabela I.

Tabela I - Distribuição da quantidade e da porcentagem de alunos do $9^{\circ}$ ano cientificamente alfabetizados e não alfabetizados

\begin{tabular}{c|c|c|c|c|c}
\multicolumn{2}{c|}{ Cientificamente alfabetizados } & \multicolumn{2}{c|}{ Cientificamente não alfabetizados } & \multicolumn{2}{c}{ Total } \\
\hline Qtd. & $\%$ & Qtd. & $\%$ & Qtd. & $\%$ \\
\hline 29 & $15,3 \%$ & 160 & $84,7 \%$ & 189 & $100 \%$ \\
\hline
\end{tabular}

Fonte: elaboração própria.

É preciso ressaltar que a aplicação do Teste de Alfabetização Científica Básica foi realizada no início do ano letivo e que, portanto, os conteúdos de Ciências referentes ao $9^{\circ}$ ano não foram trabalhados com esses alunos. Esse fato poderia ter influenciado no resultado do estudo, já que dos 1 I 0 itens do teste, 2 I eram referentes aos conteúdos desse ano, cuja quantidade de acertos foi de 56,5\%.

A análise dos resultados por sub teste revelou que não houve grande discrepância entre eles. $\bigcirc$ sub teste da natureza da Ciência apresentou uma taxa de 49,2\% de acertos, enquanto os sub testes do conhecimento do conteúdo da Ciência e do impacto da Ciência e Tecnologia na sociedade apresentaram, respectivamente, 55,2\% e 53,6\% de acertos. Esses dados são apresentados na Tabela 2.

Tabela 2 - Índice da porcentagem de acertos por subteste

\begin{tabular}{c|c|c|c|c|c}
\hline \multicolumn{2}{c|}{ STNC } & \multicolumn{2}{c|}{ STCC } & \multicolumn{2}{c}{ STICTS } \\
\hline Itens & $\%$ de acertos & Itens & \% de acertos & Itens & $\%$ de acertos \\
\hline 22 & $49,2 \%$ & 72 & $55,2 \%$ & 16 & $53,6 \%$ \\
\hline
\end{tabular}

Fonte: elaboração própria.

Percebe-se que não existe prevalência de acertos em nenhum sub teste e que em todos eles este número ficou próximo dos 50\%, mostrando certa uniformidade de conhecimentos por parte dos alunos. Esse resultado corrobora, em parte, com aqueles encontrados pelo roteiro de comparação entre a matriz do programa Science for All Americans e os Planos de ensino de Ciências do Colégio, já que, em relação ao sub teste da natureza da Ciência, a média de acertos foi de 49,2\%, sendo que 40,9\% dos itens (9 de 22 itens) estão contemplados nos Planos de Ensino de Ciências. Enquanto no sub teste dos conhecimentos dos conteúdos da Ciência a média de acertos foi de 55,2\%, um pouco abaixo do esperado, tendo em vista que a porcentagem de itens contemplados no Plano de Ensino foi de 73,6\% (53 de 72 itens).

O sub teste que apresentou a maior discrepância dos dados foi o do impacto da Ciência e Tecnologia na sociedade, cuja média de acertos foi de 53,6\%, enquanto apenas 6,2\% dos itens ( I de |6) estão contemplados nos Planos de ensino de Ciências do Colégio. Levando em consideração que os conceitos presentes nos itens deste sub teste estão relacionados, principalmente, à importância e aos 
efeitos da Tecnologia na sociedade e que os alunos que participaram do teste pertencem a uma geração com grande influência e criação de novas tecnologias, pode-se presumir que esse conhecimento, embora não tenha sido trabalhado nas aulas de Ciências, pode, além de ter sido trabalhado em outras disciplinas, ser resultado da própria vivência pessoal dos alunos.

O fato de apresentar uma média de acertos muito superior à quantidade de itens presentes nos Planos de ensino de Ciências não isenta a responsabilidade do ensino de Ciências do Colégio de contemplar os conceitos relativos aos impactos da Ciência e Tecnologia na sociedade. Da mesma forma, os conteúdos referentes aos dois outros sub testes também devem ser melhor abrangidos, já que a média de acertos nos três sub testes não ultrapassou 60\% e que apenas 15,3\% dos alunos podem ser considerados cientificamente alfabetizados.

Nota-se, também, que não há discrepância na quantidade de itens respondidos pela opção "não sei" em cada sub teste. Os itens relacionados aos sub testes da natureza da Ciência, dos conhecimentos dos conteúdos da Ciência e do impacto da Ciência e Tecnologia na sociedade apresentaram, respectivamente, $27,6 \%, 23 \%$ e 22,9\% das respostas assinaladas nessa alternativa.

Apesar de semelhantes, esses dados corroboram com aqueles referentes à quantidade de itens de cada sub teste com a porcentagem de acertos abaixo de 50\%. Nessa análise, evidencia-se que 50\% dos itens do sub teste da natureza da Ciência, 44,5\% dos itens do conhecimento do conteúdo da Ciência e 37,5\% dos itens do sub teste do impacto da Ciência e Tecnologia na sociedade se enquadram nessa categoria. Esses dados são apresentados na Tabela 3.

Tabela 3 - Índice da quantidade e porcentagem de itens por sub teste com média de acertos abaixo de 50\%

\begin{tabular}{c|c|c|c|c|c|c|c}
\hline \multicolumn{2}{c|}{ STNC } & \multicolumn{2}{c|}{ STCC } & \multicolumn{2}{c|}{ STICTS } & \multicolumn{2}{c}{ TACB } \\
\hline $\begin{array}{c}\text { Número de } \\
\text { itens }\end{array}$ & $\%$ de itens & $\begin{array}{c}\text { Número de } \\
\text { itens }\end{array}$ & $\%$ de itens & $\begin{array}{c}\text { Número de } \\
\text { itens }\end{array}$ & $\%$ de itens & $\begin{array}{c}\text { Número de } \\
\text { itens }\end{array}$ & $\%$ de itens \\
\hline II & $50 \%$ & 32 & $44,5 \%$ & 6 & $37,5 \%$ & 49 & $44,5 \%$ \\
\hline
\end{tabular}

Fonte: elaboração própria.

\section{CONCLUSÕES DO ESTUDO}

As análises realizadas neste estudo indicaram que os resultados dos alunos da população estudada foram insatisfatórios em relação ao Teste de Alfabetização Científica Básica, evidenciando que apenas 15,3\% dos alunos do $9^{\circ}$ ano do Ensino Fundamental do Colégio puderam ser considerados cientificamente alfabetizados, enquanto os outros $84,7 \%$ não atingiram a quantidade mínima de acertos nos três sub testes utilizados para a coleta dos dados.

Quanto à análise dos Planos de ensino de Ciências do Colégio, constatou-se a ausência de diversos conceitos relacionados à Alfabetização Científica presentes na matriz do programa Science for All Americans, 
principalmente daqueles referentes aos sub testes da natureza da Ciência e dos impactos da Ciência e Tecnologia na sociedade. Notou-se que as porcentagens de itens desses dois sub testes contemplados nos Planos de Ensino de Ciências foram, respectivamente, de apenas 40,9\% e 6,2\%. Em relação ao sub teste do conhecimento do conteúdo de Ciências, $73,6 \%$ dos conceitos presentes na matriz do programa Science for All Americans estavam contemplados pelos Planos de Ensino de Ciências do Colégio.

A ausência desses conceitos nos conteúdos de sala de aula gera uma grande defasagem nos conhecimentos científicos aprendidos pelo aluno. Forma-se uma lacuna no ensino das Ciências, deixando de abordar conteúdos relacionados às diversas áreas da Ciência, como, por exemplo: saberes sobre o papel do cientista, o método científico e sua aplicação nas pesquisas, a relação e do impacto da Ciência e da Tecnologia na sociedade; sobre os processos físicos e químicos, como a composição da matéria, as transformações de energia que ocorrem na Terra e no Universo e as forças que atuam nesses sistemas; sobre o meio ambiente, conceitos relacionados à origem e evolução da vida, ao ciclo da matéria e ao fluxo de energia, à genética, hereditariedade e desenvolvimento da vida; e ao organismo humano, ao seu crescimento, desenvolvimento e saúde e à sua relação com o ambiente.

Fica evidente, portanto, que o ensino de Ciências do Colégio não trabalha a maior parte dos conteúdos propostos pelo Science for All Americans que visam à Alfabetização Científica. Considerando que os conhecimentos referentes a esses conteúdos foram baseados nas três dimensões de Alfabetização Científica propostas por Miller (1983), amplamente reconhecidas pelos pesquisadores na área do Ensino de Ciências (CAMARGO et al.; 20I I; LAUGKSCH; SPARGO, 1999; LORENZETTI; DELIZOICOV, 200 I; MILLER, I983; NASCIMENTO-SCHULZE, 2006; NASCIMENTO-SCHULZE; CAMARGO; WACHELKE, 2006; OLIVEIRA, W. F. A. de; SILVA-FORSBERG, M. C., 20II; SANTOS, 2007; SASSERON; CARVALHO, 2008), a recomendação básica que o presente estudo nos indica é, além da necessidade de os professores do Colégio aprofundarem os estudos em relação às diretrizes indicadas pelo programa Science for All Americans, que eles revejam e reelaborem seus Planos de Ensino para que esses passem a contemplar os conhecimentos necessários para que os alunos do Colégio desenvolvam a Alfabetização Científica.

\section{REFERÊNCIAS}

ACADEMIA BRASILEIRA DE CIÊNCIAS. O Ensino de Ciências e a Educação Básica: propostas para superar a crise. Rio de Janeiro, 2007. 46 p.

AMERICAN ASSOCIATION FOR THE ADVANCEMENT OF SCIENCE. Project 206I: Science for all Americans. Washington: AAAS, 1989.

BRASIL. Base Nacional Comum Curricular. Brasília: MEC/SEF, 20 17. 472p. 
BRASIL. Parâmetros curriculares nacionais. Ciências naturais. Terceiro e Quarto Ciclos do Ensino Fundamental. Brasília: MEC/SEF, 1997. 136p.

CAMARGO, A. N. B. de; PILAR, F. D.; RIBEIRO, M. E. M.; FANTINEL, M.; RAMOS, M. G. Alfabetização Científica: a evolução ao longo da formação de licenciandos ingressantes, concluintes e de professores de química. Momento: diálogos em educação, Rio Grande, v. 2, n. 20, p. 19-29, ago. 201 I .

CANIÇALI, M. A. F. Análise pedagógica do Clube de Ciências como extensão escolar nos anos finais do Ensino Fundamental: em busca da Alfabetização Cientíica com enfoque CSTA. 20 | 4 . I | 4 f. Dissertação (Mestrado) - Curso de Programa de Pós-graduação em Educação em Ciências e Matemática, Instituto Federal do Espírito Santo, Vitória, 2014.

CARVALHO, L. M de. A natureza da Ciência e o ensino das Ciências Naturais: tendências e perspectivas na formação de professores. Pro-posições, Campinas, v. I2, n. I, p. I39- I50, mar. 2001.

CHASSOT, A. Alfabetização Científica: questões e desafios para a educação. ljuí: Unijuí, 2000.

CHASSOT, A. Alfabetização Científica: uma possibilidade para a inclusão social. Revista Brasileira de Educação, Rio de Janeiro, n. 22, p. 89-100, abr. 2003.

INSTITUTO NACIONAL DE ESTUDOS E PESQUISAS EDUCACIONAIS ANÍSIO TEIXEIRA (INEP). Indicadores Educacionais. Brasília: Ministério da Educação, 2014.

INSTITUTO NACIONAL DE ESTUDOS E PESQUISAS EDUCACIONAIS ANÍSIO TEIXEIRA (INEP). Matriz de avaliação de Ciências. Brasília: Ministério da Educação, 2015.

KRASILCHIK, M. Reformas e realidade: o caso do ensino das Ciências. São Paulo em Perspectiva, São Paulo, v. I4, n. I, p. 85-93, mar. 2000.

LAUGKSCH, R. C. Scientific Literacy: a conceptual overview. Science Education, Malden, v. 84, n. I, p. 7I-94, jan. 2000.

LAUGKSCH, R. C.; SPARGO, P. E. Scientific literacy of selected South African matriculants entering tertiary education: a baseline survey. South African Journal of Science, Petroria, v. 95, n. I 0, p. 427-432, out. 1999.

LAUGKSCH, R. C.; SPARGO, P. E. Construction of a paper-and-pencil test of basic scientific literacy based on selected literacy goals recommended by the American Association for the Advancement of Science. Public Understanding of Science, London, v. 5, n.4, p. 331-359, out. 1996.

LORENZETTI, L.; DELIZOICOV, D. Alfabetização Científica no contexto das séries iniciais. Ensaio Pesquisa em Educação em Ciências, Belo Horizonte, v. 3, n. I , p. 37-50, jun. 2001.

MARTELLI, J. M. Os desafios da prática pedagógica do ensino de Ciências ensino de Ciências biológicas frente às mudanças de paradigmas. 2004. 85 f. Dissertação (Mestrado) - Curso de Pós-graduação em Educação, Pontifícia Universidade Católica do Paraná, Curitiba, 2004.

MILLER, J. D. Scientific literacy for effective citizenship. In: YAGER, Robert E. (Ed.),

Science/Technology/Society as Reform in Science Education. New York: State University of New York Press, 1996.

MILLER, J. D. Scientific literacy: a conceptual and empirical review. Daedalus, Massachusetts, v. I I 2, n. 2, p. 29-48, mar./maio 1983. 
NASCIMENTO, F.; FERNANDES, H. L.; MENDONÇA, V. M. O ensino de Ciências no Brasil: história, formação de professores e desafios atuais. Revista História, Sociedade e Educação no Brasil, Campinas, n.39, p. 225-24, set. 2010.

NASCIMENTO-SCHULZE, C. M. Um estudo sobre Alfabetização Científica com jovens catarinenses. Psicologia: Teoria e Prática, Santa Catarina, v. 8, n. I, p.95- 106, 2006.

NASCIMENTO-SCHULZE, C. M.; CAMARGO, B.; WACHELKE, J. Alfabetização Científica e representações sociais de estudantes de ensino médio sobre ciência e tecnologia. Arquivos Brasileiros de Psicologia, Santa Catarina, v. 58, n. 2, p.24-37, jan. 2006.

OLIVEIRA, W. F. A. de; SILVA-FORSBERG, M. C. Níveis de Alfabetização Científica de estudantes da última série do Ensino Fundamental. In: ENCONTRO NACIONAL DE PESQUISA EM EDUCAÇÃO EM CIÊNCIAS, 201 I, Campinas. Anais [...]. Rio de Janeiro: Abrapec, 20 I I. p. I - I I.

QEDU. Matrículas e Infraestrutura. [S.I.:s.n.], [20--a]. Disponível em:

http://www.qedu.org.br/escola// 89216-santa-teresinha-colegio-salesiano/sobre. Acesso em: I 4 abr. 2016.

QEDU. Taxas de rendimento. [S.I.:S.n.], [20--b]. Disponível em http://www.qedu.org.br/escola// 89216-santa-teresinha-colegio-salesiano/taxas-rendimento. Acesso em: 15 abr. 2016.

SANTOS, P. R. dos. O Ensino de Ciências e a Ideia de Cidadania. Mirandum, Porto, v. 10, n. 17, p. 2534. 2006.

SANTOS, W. L. P. Educação científica na perspectiva de letramento como prática social: funções, princípios e desafios. Revista Brasileira de Educação, Brasília, v. I2, n. 36, p.474-550, dez. 2007.

SASSERON, L. H.; CARVALHO, A. M. P. de. Almejando a Alfabetização Científica no Ensino Fundamental: a proposição e a procura de indicadores do processo. Investigações em Ensino de Ciências, São Paulo, v. 13, n. 3, p.333-352, jul. 2008.

TEIXEIRA, P. M. M. A educação científica sob a perspectiva da pedagogia histórico-crítica e do movimento C.T.S. No ensino de Ciências. Ciência e Educação, Bauru, v. 9, n. 2, p. I77-190, out. 2003.

VIECHENESKI, J. P.; CARLETTO, M. R. Iniciação à Alfabetização Científica nos anos iniciais: contribuições de uma sequência didática. Investigações em Ensino de Ciências, Porto Alegre, v. I 8, n. 3, p. 525-543, 2013.

VIECHENESKI, J. P.; LORENZETTI, L.; CARLETTO, M. R. Desafios e práticas para o ensino de Ciências ensino de Ciências e Alfabetização Científica nos anos iniciais do Ensino Fundamental. Atos de Pesquisa em Educação, Blumenau, v. 7, n. 3, p. 853-876. set./dez. 2012. 